\title{
Assessment of the radiological situation resulted by the accidental release of fuel particles
}

\author{
V. Kashparov \\ Ukrainian Institute of Agricultural Radiology, Mashinostroiteley Str. 7, \\ Kiev Region, 018162 Chabany, Ukraine
}

\begin{abstract}
Physical-and-chemical properties of Chernobyl hot particles (radionuclide and dispersal composition, nuclear fuel burn-up and radionuclides fractionation, composition of particle matrix etc.) including the fuel particles as specific form of Chernobyl radioactive fall-out were studied [1]. Attempt to reconstruct the conditions of the fuel particles (FP) formation during the accident was done [2,3]. Oxidisation of nuclear fuel was shown to be one of the main mechanisms of FP formation during the ChNPP accident [4]. Maps of the near zone of Chernobyl accident contamination with radionuclides contained in deposited fuel particles were built [5]. It was shown that previous assessments of ${ }^{90} \mathrm{Sr}$ and transuranic elements contents in soils of the $30-\mathrm{km}$ zone has been 3-4-times overestimated. Dependencies of the fuel particles dissolution rate on level of FP matrix oxidation and acidity of a medium both for natural conditions, and model media were obtained [6,7]. Prognosis of the plants contamination dynamics along the fuel traces of radioactive fall-outs was done [6,8]. Problems of the secondary radionuclides transfer in natural conditions, due to technogenic action to soil [9] and forest fires [10], as well as a significance of the FP inhalation intake into buman body [11,12] are considered. Parameters of metabolism of FP-associated radionuclides in agricultural animals organism were obtained [13].
\end{abstract}

\section{INTRODUCTION}

Chernobyl radioactive fall-out is represented by a fuel component, i.e. particles of fine-dispersed nuclear fuel (fuel particles), and a condensed component, formed as a result of condensation of volatile fission products (radioisotopes of $\mathrm{I}, \mathrm{Te}, \mathrm{Cs}$ and, to low extent, $\mathrm{Sr}$ and $\mathrm{Ru}$ released during the high temperature annealing of nuclear fuel) on surface of different carriers [1, 4]. Fuel particles (FP) being in radioactive fall-outs are considered to be the specific peculiarity of ChNPP accident. Near $30-\mathrm{km}$ zone of the accident (about $2000 \mathrm{~km}^{2}$ ) was contaminated mainly by FP containing the main part of released from the reactor involatile radionuclides including biologically significant ${ }^{90} \mathrm{Sr}$, radioisotopes of plutonium and americium. Fuel particles were found at the long distance from ChNPP in many European countries. Caesium spots (condensed component) outside the near zone were formed due to ${ }^{137} \mathrm{Cs}$ deposition with rains.

A number of fundamental studies devoted to artificial radionuclides behaviour in the environment both after global fall-outs in consequence of nuclear weapon tests, large radiation accidents, and in model experiments with water soluble radionuclide species and various radioactive particles was carried out during last 50 years. But the first results obtained at the fuel traces of Chernobyl radioactive fall-outs shown the lack of applicability of previously existing knowledge on radionuclide behaviour. For example, radionuclides on fuel traces of radioactive fall-outs were characterised by significantly lower mobility and biological availability comparing to condensed form of fall-outs, both global, and Chernobyl ones. Therefore at the first years of Chernobyl accident the predicted rates of radionuclides migration in the near zone were overestimated (it concerns mostly ${ }^{90} \mathrm{Sr}$ ). Fuels particles have been dissolving in past and still are dissolving now. It determines an increase of plant contamination with ${ }^{90} \mathrm{Sr}$ and the radionuclide migration into surface and ground waters. In present time, $90 \mathrm{Sr}$ leaching from fuel particles causes the basic radioactive flow-out from the territory of Exclusive zone.

Lack of knowledge on behaviour of radionuclides released in the environment in composition of the irtadiated nuclear fuel particles matrix didn't allow to estimate the radiological situation in the near zone during the ChNPP accident correctly and to predict its change in a future, as well as to optimise the countermeasures application. 
At evaluation of radiological situation (influence of external irradiation to human and animals and of internal irradiation at inhalation and at peroral intake of radionuclides into organism), physical and chemical characteristics of FP-associated radionuclides are mostly expressed:

- at the formation of radioactive contamination of territory;

- at the inhalation intake of radionuclides during the radioactive cloud pass and at the wind resuspension, in radionuclide metabolism in an organism and formation of doses;

- at radionuclides migration in soil, determining the dynamics of external irradiation dose rate and the contamination of surface and ground waters, as well as the changes of radionuclides biological availability in time, determining the levels of plant and agricultural production radioactive contamination and the radionuclides intake into human organism;

- at the peroral intake of radionuclides into agricultural animals organism, radionuclides metabolism and radioactive contamination of agricultural production.

Significance of environmental behaviour study of radionuclides, especially of those contained in Chernobyl fuel particles is determined by all factors mentioned above, both for elimination of the Chernobyl accident consequences, and for its experience use in another hypothetical accidents with irradiated nuclear fuel particles release, and for the needs of the radioactive waste burying.

\section{PHYSICO-CHEMICAL PROPERTIES OF THE FUEL PARTICLES AND MECHANISMS OF THEIR FORMATION DURING THE ChNPP ACCIDENT}

In the near zone of ChNPP accident, hot particles of more then $10 \mu \mathrm{m}$ size are presented by the particles of dispersed Chernobyl nuclear fuel mainly $(97 \%)$, i.e. fuel particles. Specific activity of these particles corresponds to specific activity of the fuel at the moment of accident excluding volatile high mobile radionuclides of ${ }^{134,137} \mathrm{Cs}$. Burn-up distribution of the fuel particles of more then $10 \mu \mathrm{m}$ size indicates that they were released from a limited part of the reactor where burn-up values were lower comparing with average fuel burn-up in the 4th unit of ChNPP at the moment of accident [1]. Ratios between ${ }^{90} \mathrm{Sr}$, ${ }^{95} \mathrm{Zr},{ }^{106} \mathrm{Ru},{ }^{125} \mathrm{Sb},{ }^{134} \mathrm{Cs},{ }^{137} \mathrm{Cs},{ }^{144} \mathrm{Ce},{ }^{154} \mathrm{Eu},{ }^{155} \mathrm{Eu}$ and TUE in fuel particles were estimated using the experimental data that allows calculating of territory contamination by main radiological important radionuclides included into fuel component of fall-outs. The database "Hot particles" was created allowing integrating the information.

Air-oxidation at 673 - $11730 \mathrm{~K}$ of real irradiated Chernobyl nuclear fuel destroys it into small particles. Their dispersal composition is well described by lognormal law of distribution [4] and corresponds to the dispersal composition of radioactive fall-outs [6]. Parameters of distribution for FP dispersal composition were obtained [4,7]. Median radius of particles doesn't depend on annealing temperature and decreases with annealing duration reaching the nuclear fuel grain (crystallite) size $(3 \mu \mathrm{m})$. On the base of dispersal composition and real Chernobyl fuel particles matrix composition it can be concluded that nuclear fuel oxidation was one of the main mechanisms of the fuel particles formation during the ChNPP accident.

At the air-oxidation and dispersion of real irradiated oxide nuclear fuel, even at $673 \circ \mathrm{K}$, ruthenium leakage as volatile $\mathrm{RuO}_{4}$ and following condensation on iron group materials took place. Ruthenium oxidation and leakage was observed from grain surface only, and didn't exceed few units of per cent in relation to its content in fuel matrix [4].

Increase of the real fuel particles annealing temperature in an inert medium from 1273 to $22730 \mathrm{~K}$ is accompanied by growth of radionuclides relative leakage in following consequence: caesium isotopes> europium isotopes $>$ cerium isotopes $>$ americium isotopes $>$ ruthenium, plutonium, curium isotopes. At $2273 \circ \mathrm{K}$ the relative leakage of all measured radionuclides from the real fuel particles exceeds $90 \%$ during $100 \mathrm{~min}$ annealing period.

Absence of ${ }^{144} \mathrm{Ce},{ }^{154,155} \mathrm{Eu}$ and ${ }^{125} \mathrm{Sb}$ fractionation in the real Chernobyl fuel particles and relatively low depletion by ${ }^{90} \mathrm{Sr}$ and ${ }^{134,137} \mathrm{Cs}$ show that the particles released from the unit were in rather "soft" temperature conditions during the ChNPP accident or were heating during small period of time.

A large array of data was obtained during works on modelling of the hot particles formation during the accident and fractionation (leakage) of fission products at the high temperature annealing of particles. 
Along with data on real radionuclides fractionation in the Chernobyl fuel particles it permitted to assess the effective temperature and period of fuel annealing during the ChNPP accident $[2,3]$. The attempt was done and a possibility was shown to determine the localisation of the source of initial nuclear fuel release from the reactor during the $\mathrm{ChNPP}$ explosion [3].

\section{TERRITORY CONTAMINATION WITH THE RADIONUCLDES OF FUEL COMPONENT OF RADIOACTIVE FALL-OUTS}

Detailed maps of the Exclusive zone contamination with radionuclides of the fuel component of Chemobyl radioactive fall-outs were absent till 1997 because of impossible use of distant measurements and large complexity of works. Hence, the complete work on correction of information on the ChNPP near zone contamination aiming the rehabilitation activity planning was carried out in 1997 [5]. First of all, works were directed to the $30-\mathrm{km}$ zone mapping by ${ }^{90} \mathrm{Sr}$ and TUE because the content of mobile radiostrontium in soil increased due to fuel particles dissolution.

A significant methodical work on sampling and measurements optimisation was ahead of the beginning of a large-scale sampling [14]. Soil samples were collected in 30-km zone of ChNPP by regular mesh with a step about $1 \mathrm{~km}$ (at sites with higher gradients of contamination density the distance between points of sampling was in $0.1-0.5 \mathrm{~km}$ range). Standard radiochemical methods were used for soil samples measurements. These actions permitted to create detailed maps of ${ }^{90} \mathrm{Sr}$ and TUE contamination of $30-\mathrm{km} \mathrm{ChNPP}$ zone. Integration of surface territory contamination shown, that total contents of radionuclides in $30-\mathrm{cm}$ soil layer of the ChNPP $30-\mathrm{km}$ zone outside the ChNPP territory itself (without locals of radioactive wastes buries and pond-cooler) at 01.01 .2000 can be estimated as: ${ }^{90} \mathrm{Sr}-\mathbf{8 . 1 E}+14$ $\mathrm{Bq} ;{ }^{137} \mathrm{Cs}-2.9 \mathrm{E}+15 \mathrm{~Bq} ;{ }^{144} \mathrm{Ce}-1.0 \mathrm{E}+11 \mathrm{~Bq} ;{ }^{154} \mathrm{Eu}-1.5 \mathrm{E}+13 \mathrm{~Bq}$; ${ }^{238} \mathrm{Pu}-8.78 \mathrm{E}+12 \mathrm{~Bq} ;{ }^{239+240} \mathrm{Pu}-$ $1.54 \mathrm{E}+13 \mathrm{~Bq} ;{ }^{241} \mathrm{Pu}-5.64 \mathrm{E}+14 \mathrm{~Bq} ;{ }^{241} \mathrm{Am}-2.06 \mathrm{E}+13 \mathrm{~Bq}$. The total content of radionuclides released in the fuel particles corresponds to $0.4-0.5 \%$ of their inventory in the $4^{\text {th }}$ unit of Chernobyl NPP and 3-4 times lower then earlier generally used values. A half of radiostrontium activity localised in an upper soil layer of the near zone is located on $2 \%$ of the $30-\mathrm{km}$ zone territory only, and $80 \%$ of the total content is located on $11 \%$ of the territory. Terrestrial density of contamination with ${ }^{90} \mathrm{Sr}$ and TUE beyond the Exclusive zone borders is comparable with levels of global fall-outs after nuclear weapons tests in atmosphere. Density of territory contamination with ${ }^{90} \mathrm{Sr}$ and ${ }^{238} \mathrm{Pu}$ in regions bordering on $30-\mathrm{km}$ zone doesn't exceed $40 \mathrm{kBq} / \mathrm{m}^{2}$ and $100 \mathrm{~Bq} / \mathrm{m}^{2}$, respectively. Therefore, previously used estimates of radionuclides content belonged to fuel component of radioactive fall-outs in soil, and, hence, their release from the unit during the accident has been significantly overestimated.

\section{KINETICS OF THE FUEL PARTICLES DISSOLUTION IN SOILS IN NATURAL CONDITIONS AND IN MODEL MEDIA}

Method of assessment of the fuel particles dissolution rate in soil and dynamics of radionuclide leaching into mobile forms in natural conditions was elaborated on the base of exchangeable Chernobyl ${ }^{90} \mathrm{Sr}$ and water-soluble ${ }^{85} \mathrm{Sr}$ applied to soil share measurements $[6,8]$.

Obtained data shown higher chemical stability of the fuel particles in soil in the narrow western trace of radioactive fall-outs, formed after the first release of the ChNPP accident, in comparison with the particles released in other directions and formed as a result of nuclear fuel oxidation. Hence, the fuel particles (separate grains, crystallites of uranium oxide) with median diameter of about $6 \mu^{\mathrm{m}}$ and their aggregates can be divided into 2 groups [7]:

- non-oxidised fuel particles of the first release (26.04.86), formed as a result of mechanical destruction of nuclear fuel and created the narrow western trace (about 10-15\% of activity of long-living radionuclides in composition of fuel particles outside the ChNPP territory);

- particles formed as a result of nuclear fuel oxidation (26.04-5.05.86), created northern (60-70\% of activity) and southern (about $20-25 \%$ of activity) traces of fuel fall-outs. 
Analysis of soil physico-chemical properties affect to FP dissolution shows, that rate of the particles of the same group dissolution is correlated with acidity of water extract $\mathrm{pH}_{\mathrm{H} 2 \mathrm{O}}$ to the biggest extent. Particles remained best of all in neutral soils $\left(\mathrm{pH}_{\mathrm{H} 2 \mathrm{O}}>6\right)$ independently upon direction and distance from ChNPP. So, even in 1998 at the distance of more then $30 \mathrm{~km}$ to the south the main part of ${ }^{90} \mathrm{St}$ activity was in the immobile state in composition of the fuel particles (about 50-70\%) in cultivated neutral soils ( $\mathrm{pH}_{\mathrm{H} 2 \mathrm{O}}$ about 7 ) used in agriculture after the accident.

It was shown experimentally, that the fuel particles dissolution rate in natural conditions is determined by the particles properties, i.e. level of matrix oxidation, as well as medium acidity. The phenomenon was confirmed by model experiments on kinetics of the Chernobyl irradiated nuclear fuel particles dissolution in solutions with pH 3-9 study [7]. The lowest rate of FP dissolution was observed in a neutral medium. Rate of FP dissolution increased in alkaline and acidic media. Rate of non-oxidised particles dissolution was to the order of magnitude lower then respective of the particles formed as a result of nuclear fuel oxidation.

Parameters of the fuel particles dissolution depending on their genesis and medium acidity were obtained as a result of fulfilled works [6-8]. Period of FP half-dissolution varies from 14 to 1 year with soil acidity increase $\left(\mathrm{pH}_{\mathrm{H} 2 \mathrm{O}}\right.$ from 7 till 4). Application of obtained parameters for description of dynamics of ${ }^{90} \mathrm{Sr}$ transfer from the fuel particles matrix to soil provides a good accordance with the literature data on its species in soil on fuel traces of Chernobyl release in different periods after the accident [8].

Obtained dependencies of transformation constants for the Chernobyl fuel particles of various geneses on soil acidity allowed to predict radionuclides leaching from matrix to soil solution and their involving into migration processes, and root accumulation by plants as well.

Rate of FP dissolution would vary in different parts of $30-\mathrm{km}$ zone that should be taken into account in the assessment and prediction of radiological situation. So, the period of the fuel particles halfdissolution exceeds 10 years on $16 \%$ of the $30-\mathrm{km}$ zone territory, mounts to $7-10$ years on $15 \%$ of the territory, mounts to $4.6-7$ years on $25 \%$ of the territory, mounts to $3.5-4.6$ years on $20 \%$ and is less then 2 years on $24 \%$ of the territory.

On the base of created map of the fuel particles transformation constants the spatial estimation of radionuclides weathering from FP matrix into soil in natural conditions in 5, 10, 15, 20 and 30 years after accident was done. High rates of the fuel particles dissolution on the bigger area of $30-\mathrm{km}$ zone are determined by sufficiently high soil acidity. The last is explained by long-term absence of ameliotation (liming) actions because these lands were withdrawn from agricultural use after the accident.

\section{DYNAMICS OF PLANTATION CONTAMINATION ON FUEL TRACES OF RADIOACTIV FALL-OUTS}

Fuel particles can be considered as special depot for delay of involving radionuclides into migration processes in soil and transfer to plant root system (Fig.1). That accompanied by principally other levels and dynamics of radionuclides content in biologically available form in root layer of soil and in plants comparing with condensed fall-outs [6,8]. In dependence on FP dissolution rate, root contamination of plants by ${ }^{90} \mathrm{Sr}$ grows in first years after the accident and reaches the maximum at 2-20 years. Maximum level of plant contamination with ${ }^{90} \mathrm{Sr}$ is late reached on neutral soils (in 20-25 years), the level of contamination about 2.5 lower then the respective maximum on condensed traces of fall-outs (distinctions mounts to 10 times in the first years after the accident).

Taking into account the dynamics of the fuel particles dissolution in soil the conclusion could be done about stabilisation of radiological situation on fuel traces of radioactive fall-outs nowadays. Less then $50 \%$ of total contents of radionuclides in soil are associated with the fuel particles matrix (i.e., are presented in low available form). Accounting the radioactive fission of ${ }^{90} \mathrm{Sr}$ the absolute content of its mobile form in neutral soils would increase 10-20 years more, but its maximum content wouldn't exceed the present level more then by $20 \%$. Content of mobile ${ }^{90} \mathrm{Sr}$ forms in acidic soils reached its maximum and will decrease in time, plants contamination will decrease simultaneously.

Root contamination of plants with ${ }^{137} \mathrm{Cs}$ is observed to decrease significantly in time for condensed form of fall-outs. As for fuel component, both decrease and increase of plant contamination 
can occur in dependence on FP dissolution rate and a part of condensed ${ }^{137} \mathrm{Cs}$. At the short distances from ChNPP where minimum fraction of condensed radiocaesium is observed, root contamination of plants with ${ }^{137} \mathrm{Cs}$ increased during the first 2-6 years after the accident. In ten years after the accident root contamination of plants on arable lands would decrease and faint difference between fuel and condensed form of radioactive fall-outs be observed.
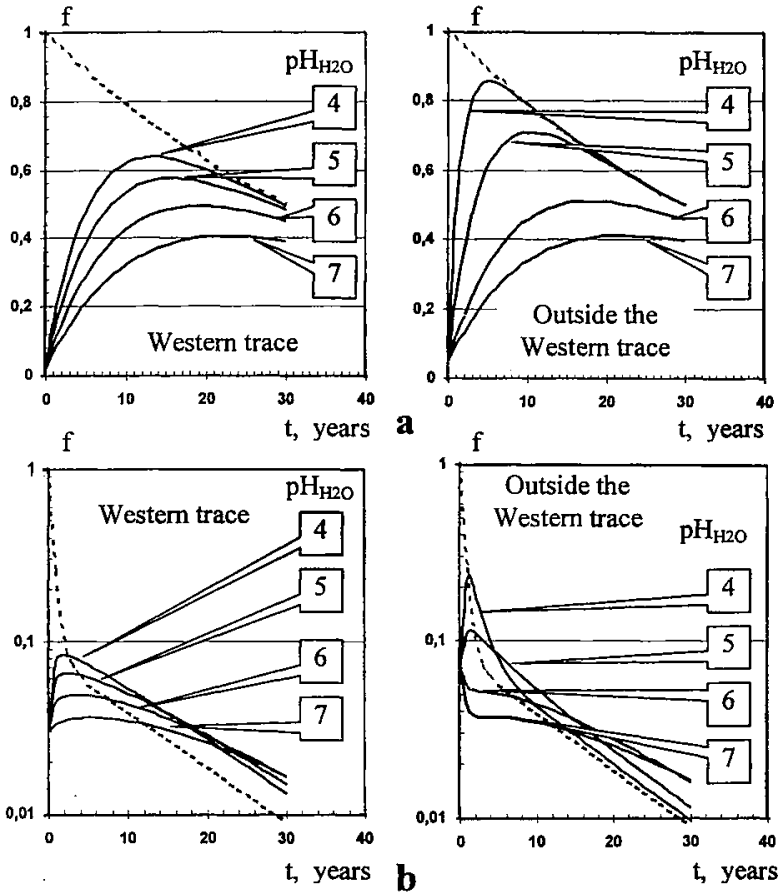

Figure 1. Relative dynamics of ${ }^{90} \mathrm{Sr}(\mathrm{a})$ and ${ }^{137} \mathrm{Cs}$ (b) plantation contamination (f) on condensed and fuel, fall-outs.

Radionuclide out-fluxes by plants and respective human doses due to agricultural products consumption would be lower on fuel traces of radioactive fall-outs comparing with condensed traces of radioactive fall-outs. About $50 \%$ of total possible out-flux of ${ }^{137} \mathrm{Cs}$ activity transfers into plantation during less then 4 first years on condensed traces (70\% during 10 years, about $90 \%$ during 30 years). The relative out-flux of ${ }^{137} \mathrm{Cs}$ and ${ }^{90} \mathrm{Sr}$ from neutral soils on fuel traces is equal to $\sim 25 \%, 55 \%$ and $\sim 5 \%, 23 \%$ for first 10 and 30 years, respectively. Integral ${ }^{90} \mathrm{Sr}$ out-flux by plants on fuel traces of radioactive fallouts with minimum FP dissolution rate would be 2.5 times lower then on condensed traces.

\section{THE SECONDARY TRANSFER OF RADIONUCLIDES AND THEIR INHALATION INTAKE INTO HUMAN ORGANISM}

As it was estimated experimentally, no significant differences in secondary wind transfer have been observed in two years after the accident between radionuclides deposited in the fuel particles and condensed forms, that is determined by a strong FP fixation by soil particles [9]. Yearly wind transfer of radionuclides in several years after the accident in normal meteorological conditions varies their contents per unit area in range $0.05-0.5 \%$ even during agricultural works, and can't influence significantly on the secondary radioactive contamination of territory and deactivated settlements. Wind resuspension increases at the agricultural measures carrying out, especially during soil cultivation, but the radionuclides flux saturation is observed at the distance $50-100 \mathrm{~m}$ from the field edge. Radionuclides airborne concentration in a lower air layer during forest fires on the contaminated territories can increase up to $10^{3}$ times (with maximum at the distance of several kilometres from the fire), but significant 
redistribution of activity and radiological danger increase beyond the 30-km ChNPP zone borders was not observed [10].

Model experiments in simulated lung liquid shown that the radioactive Chernobyl aerosols on fuel traces of radioactive fall-outs can be classified as insoluble ones when their inhalation intake into humat respiratory system is considered [12]. At the wide range of agrotechnical works, concentration an dispersal composition of the radioactive aerosols were measured just at the working places (cabs 0 tractors etc) of machine-operators considered as a critical group of population [11]. It was shown, tha even for this critical group of population on territories contaminated by the fuel particles as a resulto Chernobyl accident, effective doses formed due to radionuclides $\left({ }^{137} \mathrm{Cs}\right.$, $\left.{ }^{238-240} \mathrm{Pu},{ }^{241} \mathrm{Am}\right)$ inhalation art the order of magnitude lower then doses of external irradiation by ${ }^{137} \mathrm{Cs}$ during a year.

\section{BEHAVIOUR OF FP-ASSOCIATED RADIONUCLIDES IN ORGANISM OF AGRICULTURAL ANIMALS}

At the acute period of Chernobyl accident the fuel particles got into organism of agricultural animals at pastures with forage, sod and swallowed soil. Aiming the study of the fuel particles behaviour at their ingestion by cattle, the experiment with single feeding of animals with the model fuel particles similar to obtain after the Chernobyl NPP accident ones was performed [13]. It was found that absorption of ${ }^{90} \mathrm{Sr}$ and ${ }^{137} \mathrm{Cs}$ in blood and their removal from organism at the fuel particles ingestion are principally distinctive from respective ones at the soluble form of radionuclides ingestion. Coefficient of ${ }^{37} \mathrm{C}$ absorption in cattle organism from fuel particles $(0.8-1.4 \%)$ is considerably lower than from its soluble form (50-75\%). Peak of ${ }^{137} \mathrm{Cs}$ concentration in milk was observed in 44-68 hours after FP entering into the cattle organism. Radionuclide content decreases exponentially with a period of half-removal 58.69 hours. In 9 days after FP intake $0.11-0.17 \%$ of ingested amount ${ }^{\text {of }}{ }^{137} \mathrm{Cs}$ was removed with milk, that is by 2 orders of magnitude less than for ${ }^{137} \mathrm{Cs}$ soluble form.

\section{References}

[1] Kuriny V.D. et al., Ann. Nucl. Energy, 20/6 (1993) 415-420.

[2] Kashparov V.A. et al., Radiochemistry, 38/1 (1996) 91-95 (Russ.).

[3] Kashparov V.A. et al., Radiochemistry, 39/1 (1997) 66-70 (Russ.).

[4] Kashparov V.A. et al., Nucl. Technology, 114/1 (1996) 246-253.

[5] Kashparov V.A. et al., J. Environ. Radioactivity, 56/3 (2001) 285-298.

[6] Kashparov V.A. et al., Health Physics, 76/3 (1999) 251-259.

[7] Kashparov V.A. et al., J. Nucl. Materials, 279 (2000) 225-233.

[8] Kashparov V.A., Zvarich S.I., Protsak V.P. and Zhurba M.A. Radiochemistry, $42 / 6$ (2000) 542.549 (Russ.).

[9] Kashparov V.A., Protsak V.P., Ivanov Yu.A. and Nicholson K.W. J. Aerosol Science, 25/5 (1994) $755-761$.

[10] Kashparov V.A. et al., J. Environ. Radioactivity, 51 (2000) 281-298.

[11] Kashparov V.A., Protsak V.P.,Yoschenko V.I. and Watterson J.D. J. Aerosol Science, 25/5 (1994) 761-767.

[12] Kashparov V.A. et al., Radiochemistry, 39/1 (1997) 77-79 (Russ.).

[13] Kashparov V.A., Lazarev N.M., Yoschenko V.I. Radiating biology. Radioecology, 37/5 (1997), 804. 811 (Russ).

[14] Kashparov V.A. et al., J. Radioanalytical and Nucl. Chemistry, 246/1 (2000) 165-172. 